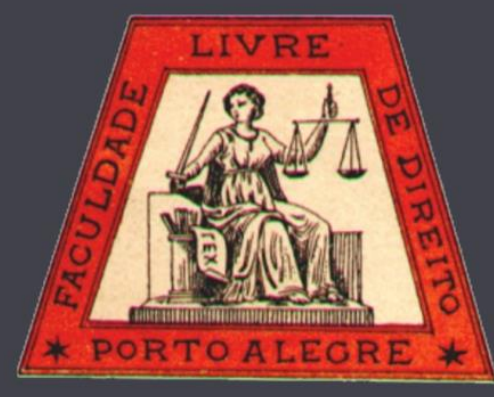

\title{
A relação entre Direito e desastres: uma análise a partir da apelação cível no 0026225-19.2005.8.19.0021 do Tribunal de Justiça do Estado do Rio de Janeiro
}

The relation between law and disasters: an analysis from the civil appeal no. 0026225-19.2005.8.19.0021 of Rio de Janeiro State Court

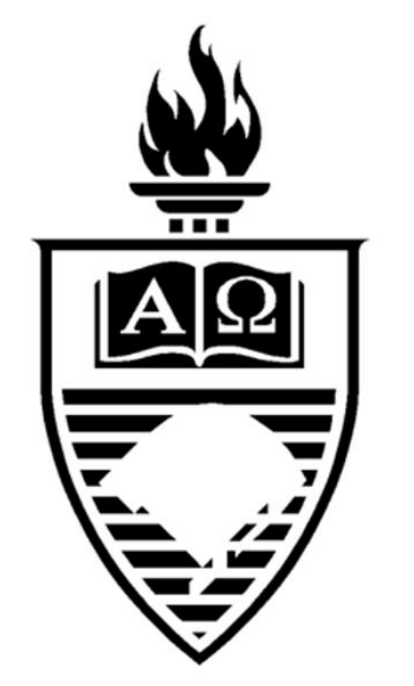

\author{
Carlos Eduardo Silva e Souza \\ Universidade Federal de Mato Grosso
}

Victor Lucas Alvim

Universidade Federal de Mato Grosso

\section{UFRGS}




\title{
A relação entre Direito e desastres: uma análise a partir da apelação cível $\mathbf{n}^{0} 0026225$ - 19.2005.8.19.0021 do Tribunal de Justiça do Estado do Rio de Janeiro
}

\author{
The relation between law and disasters: an analysis from the civil appeal no. 0026225- \\ 19.2005.8.19.0021 of Rio de Janeiro State Court
}

Carlos Eduardo Silva e Souza*

Victor Lucas Alvim**

\begin{abstract}
REFERÊNCIA
SOUZA, Carlos Eduardo Silva e; ALVIM, Victor Lucas. A relação entre Direito e desastres: uma análise a partir da apelação cível $\mathrm{n}^{\circ}$ 0026225-19.2005.8.19.0021 do Tribunal de Justiça do Estado do Rio de Janeiro. Revista da Faculdade de Direito da UFRGS, Porto Alegre, n. 35, p. 218-232, dez. 2016.
\end{abstract}

\section{RESUMO}

O presente trabalho objetiva investigar a relação entre o Direito e os desastres, tendo, como parâmetro de análise, os termos do acórdão proferido na Apelação Cível $n^{\circ}$ 0025225-19.2005.8.19.0021, que foi prolatado pelo Tribunal de Justiça do Estado do Rio de Janeiro. A problemática central está focada na percepção da existência ou não de uma relação entre a aludida ciência e o mencionado fenômeno e qual as ilações que poderiam ser tiradas dessa constatação. Nesse sentido, o trabalho é construído em quatro partes. A primeira dedica a apresentar o caso em análise, de forma a viabilizar a compreensão do acórdão eleito para o início da investigação apresentada. A segunda, por sua vez, voltase para verificar a proteção jurídica contra os desastres, focando-se a análise, sobretudo, na realidade jurídiconormativa da legislação brasileira. A terceira parte do trabalho dirige a atenção para a compreensão da tutela ambiental preventiva, a partir da gestão de riscos e perigos catastróficos. A quarta e última parte é dedicada para a compreensão da tutela ambiental reparadora e, de forma mais específica, para a responsabilidade civil em matéria catastrófica. A investigação valeu-se da pesquisa bibliográfica e documental, tendo ainda se servido do método de abordagem qualitativo de análise de dados.

\section{PALAVRAS-CHAVE}

Direito. Desastre. Catástrofe. Ambiente. Responsabilidade Civil.

\begin{abstract}
This study aims to investigate the relation between law and disasters, having as analysis parameter the terms of the judgment delivered in the Civil Appeal No. 002522519.2005.8.19.0021, which was rendered by the Rio de Janeiro State Court. The main question is focused on the perception of whether or not there is a relation between the alluded science and the mentioned phenomenon, and what are the conclusions that could be drawn from this finding. In this sense, the work is constructed in four parts. The first is dedicated to present the case in question, in order to facilitate the understanding of the judgment elected to start the presented research. The second, in turn, turns to verify the legal protection against disasters, focusing the analysis, especially, on the legalnormative reality of the Brazilian Law. The third part of the work directs attention to the understanding of the preventive environmental protection based on risk and catastrophic dangers management. The fourth and final part is devoted to the understanding of restorative environmental protection and, more specifically, to the civil liability for catastrophic matter. The research drew on bibliographic and documentary research, and still drew on qualitative approach method of data analysis.
\end{abstract}

\section{KEYWORDS}

Law. Disaster. Catastrophe. Environment. Civil liability

\footnotetext{
* Professor Adjunto na Faculdade de Direito da Universidade Federal de Mato Grosso - UFMT. Doutor em Direito pela Faculdade Autônoma de Direito de São Paulo - FADISP, 2014 e Mestre em Direito pela UFMT - Universidade Federal de Mato Grosso. Advogado.

** Acadêmico de Direito (Universidade Federal de Mato Grosso - UFMT).
} 


\section{SUMÁRIO}

Introdução. 1. O caso em Análise: o rompimento do duto PEII e a sua discussão no âmbito do acórdão proferido na Apelação No 0026225-19.2005.8.19.0021 do Tribunal de Justiça do Estado do Rio De Janeiro. 2. A proteção jurídica contra desastres. 3. Tutela ambiental preventiva: a gestão de riscos e perigos catastróficos. 4. Tutela ambiental reparadora: a responsabilidade civil em matéria catastrófica. Conclusão. Referências.

\section{INTRODUÇÃO}

O presente trabalho, utilizando a decisão do Tribunal de Justiça do Estado do Rio de Janeiro na apelação cível $\mathrm{n}^{\circ}$ 002622519.2005.8.19.0021 como objeto de comentários, tem, por finalidade, além de analisar o caso em si, realizar breves apontamentos teóricos sobre a relação entre desastres e o Direito, sob uma perspectiva ex ante e ex post ao evento danoso, visando chamar a atenção da comunidade jurídica para uma temática ainda pouco conhecida e estudada no Brasil.

A problemática central está focada na percepção da existência ou não de uma relação entre a aludida ciência e o mencionado fenômeno e quais ilações poderiam ser tiradas dessa constatação.

Nesse escopo, divide-se o trabalho em quatro partes. $\mathrm{Na}$ primeira, analisam-se as circunstâncias do desastre ocorrido na baía de Guanabara em março de 2000, bem como o relatório processual do acórdão em comento.

Em seguida, na segunda, investiga-se a relação que se tem entre o Direito e desastres, focando-se especialmente a atenção e análise aqui apresentada na realidade jurídico-normativa brasileira.

Por sua vez, a terceira perquire como se dá a tutela ambiental preventiva, a qual é realizada mediante a gestão de riscos e perigos catastróficos.

Por derradeiro, a quarta parte se dedica à tutela ambiental reparadora, analisando o instituto da responsabilidade civil aplicado ao dano catastrófico.
Para tanto, a investigação se valeu das formas de pesquisa bibliográfica e documental, servindo-se dos métodos de abordagem qualitativa da análise de dados.

\section{O CASO EM ANÁLISE: O ROMPIMENTO DO DUTO PE-II E A SUA DISCUSSÃO NO ÂMBITO DO ACÓRDÃO PROFERIDO NA APELAÇÃO No 0026225- 19.2005.8.19.0021 DO TRIBUNAL DE JUSTIÇA DO ESTADO DO RIO DE JANEIRO}

Em 18 de janeiro de 2000, conforme amplamente divulgado nos noticiários, foi rompido, em sua parte enterrada, o duto PE-II da Petrobrás, que interligava a Refinaria Duque de Caxias (REDUC), localizada no Município de Duque de Caxias-RJ, à Gerência da Baía de Guanabara (GEGUA), provocando o vazamento de 1.292.000 litros de óleo combustível na aludida baía, ocasionando um dos maiores desastres já ocorridos no Brasil à época ${ }^{1}$.

Consoante relatório de impacto ambiental produzido pelo Ministério do Meio Ambiente, diversos foram os danos ambientais provocados por este fato, sendo que alguns deles afetaram profundamente a biota da região da baía de Guanabara, exigindo um longo período, estimado em mais de dez anos, para recuperação e recomposição. Dentre as lesões ocasionadas

\footnotetext{
${ }^{1}$ Apesar de não estar presente no acórdão que será analisado, o Relatório sobre o impacto ambiental causado pelo derramamento de óleo na Baía de Guanabara, do Conselho Nacional do Meio, é um documento oficial que, eficazmente, demonstra a dimensão da catástrofe em comento, considerando que a decisão a ser comentada já toma o desastre como fato público e notório. BRASIL. Ministério do Meio Ambiente, 2001.
} 
pelo desastre, pode-se citar danos aos manguezais, às praias, aos costões rochosos, ao ambiente pelágico, ao ambiente bentônico, às aves, ao ecossistema aquático, entre outros. Outrossim, observou-se impactos sócioeconômicos, principalmente em relação à pesca, à balneabilidade, ao turismo e ao comércio (BRASIL. Ministério do Meio Ambiente, 2001). Esta catástrofe foi o fato ensejador da ação judicial cujo acórdão será analisado a seguir.

O acórdão em comento apreciou recurso de apelação cível, o qual foi interposto tanto por Paulo Gilson da Costa Almeida e Vilson da Costa Gomes, quanto pela Petrobrás, para atacar sentença que julgou parcialmente procedente ação ordinária, que versava sobre indenização por danos materiais e morais. A ementa do acórdão $^{2}$, objeto dos comentários apresentados em seguida, é a seguinte:

DIREITO AMBIENTAL. RESPONSABILIDADE CIVIL OBJETIVA. RISCO DA ATIVIDADE. DESASTRE ECOLÓGICO. FATO PÚBLICO E NOTÓRIO. DERRAMAMENTO DE ÓLEO NA BAÍA DE GUANABARA EM JANEIRO DE 2000. DANOS AO MEIO AMBIENTE. PREJUÍZOS A ATIVIDADE PESQUEIRA E CATADORA DO ENTORNO DA BAÍA. FATOS NOCIVOS INCONTROVERSOS. IMPOSSIBILIDADE MOMENTÂNEA DO EXERCÍCIO LABORATIVO E FLAGRANTE DIMINUIÇÃO NA QUANTIDADE E NA QUALIDADE DO PESCADO E NA COLETA DOS CRUSTÁCEOS. REFLEXOS NA ECONOMIA DOMÉSTICA E INDIVIDUAL DAS FAMÍLIAS DE PESCADORES E DE CATADORES. DIREITO À INDENIZAÇÃO. FIXAÇÃO DO SALÁRIO MÍNIMO COMO PARADIGMA INDENIZATÓRIO, A MÍNGUA DE OUTROS ELEMENTOS. REPERCUSSÕES DISRUPTORAS DE ORDEM MORAL E EMOCIONAL CARENTES DE INDENIZAÇÃO. A responsabilidade do $2^{\circ}$ Apelante (PETROBRÁS) pelo acidente ambiental é objetiva, nos termos do artigo $14 \S 1^{\circ}$, da Lei 6938/81, que dispõe sobre a Política Nacional do Meio Ambiente. No caso, o

\footnotetext{
${ }^{2}$ A íntegra do acórdão objeto de análise está disponível e pode ser encontrada no sítio eletrônico do Tribunal de Justiça do Estado do Rio de Janeiro. Ver: RIO DE JANEIRO. Tribunal de Justiça do Estado do Rio de Janeiro, 2005.
}

desastre ambiental é fato público e notório. A própria notoriedade do acidente ambiental atesta o nexo de causalidade entre atividade exercida pela PETROBRÁS e a impossibilidade de trabalho dos pescadores que tiravam o sustento da exploração da pesca na Baía de Guanabara e, consequentemente da dificuldade desses de auferir renda. Elementos dos autos que comprovam que os Apelantes viviam da atividade pesqueira na Baía de Guanabara, quando ocorreu o acidente. $\mathrm{O}$ fato dos Apelantes não terem sido cadastrados à época pela petrolífera, não induz a conclusão de que os mesmos não fariam jus ao recebimento de indenização pelo desastre ecológico. Ausência de prova quanto aos critérios empregados para cadastramento e pagamento dos pescadores ou de ter sido ter abrangido, no levantamento realizado, todas as famílias impactadas pelo vazamento de óleo. Caracterizado os elementos da responsabilidade civil, exsurge o dever de indenizar pelos danos morais e materiais suportados pelos Apelantes. Majoração da verba fixada a título de danos morais. Quanto ao dano material, consubstanciados naquilo que os pescadores deixaram de receber, é de se considerar o salário-mínimo legal vigente na data do fato como parâmetro mínimo para fins indenizatórios, a míngua de comprovação de renda. Conhecimento dos recursos, parcial provimento do primeiro (PAULO e outro) e desprovimento do segundo (PETROBRAS).

A ação, processada pelo rito comum ordinário, foi proposta por Paulo Gilson da Costa Almeida e Vilson da Costa Gomes em face da Petrobrás, formulando uma pretensão no sentido de obter indenização civil por danos morais e prejuízos materiais, os quais decorreram do indigitado desastre. Em síntese, como causa de pedir, os autores alegaram que eram pescadores, de maneira que, com a ocorrência dos danos ocasionados ao meio ambiente, foram afetados em sua fonte de trabalho, já que restou impossibilitado o exercício da pesca naquele local. Além disso, sustentaram a existência de dano moral ante a angústia sofrida pela falta de trabalho.

$\mathrm{Na}$ sentença prolatada pelo juízo a quo, o magistrado de piso julgou parcialmente procedente a ação, condenando a Petrobrás ao pagamento de indenização no valor de $\mathrm{R} \$$ 10.000,00 (dez mil reais) para cada autor, 
acrescido de juros de mora de $1 \%$ (um por cento), a contar do ilícito e correção monetária desde a sentença, tendo em vista a existência de dano moral no caso, já que os autores se viram impedidos de exercer a atividade pesqueira durante o período de um mês, fato este que provocou angústia nos requerentes. Diante da sucumbência recíproca, ambas as partes interpuseram recurso de apelação.

Paulo Gilson da Costa Almeida e Vilson da Costa Gomes, em linhas gerais, em suas razões recursais, argumentaram que o juiz de piso, em sua decisão, não considerou os laudos técnicos existentes nos autos, inclusive um confeccionado pelo Instituto Brasileiro do Meio Ambiente e dos Recursos Naturais Renováveis (Ibama), o qual constatou ser necessário cerca de dez anos para o meio ambiente se recompor. Além disso, sustentaram ter sofrido danos materiais, na modalidade lucro cessante, no valor de R\$ 101.148,32 (cento e um mil, cento e quarenta e oito reais e trinta e dois centavos). Ademais, requereram majoração da indenização fixada a título de danos morais, uma vez que o magistrado a quo não teria observado o princípio da proporcionalidade no arbitramento do valor.

Já a Petrobrás, em seu recurso de apelação, em síntese, sustentou que não havia dano moral a ser indenizado, nem provas nos autos dos danos materiais alegados. Ainda, a pretolífera alegou que a poluição pré-existente na baía de Guanabara era pública e notória, além de que não haveria nexo de causalidade entre os fatos narrados e os danos supostamente sofridos pelos autores.

Por sua vez, o Tribunal de Justiça do Estado do Rio de Janeiro conheceu e deu parcial provimento ao recurso interposto pelos autores, majorando a indenização fixada a título de danos morais para o valor de $\mathrm{R} \$ 20.000,00$ (vinte mil reais), condenando ainda a Petrobrás ao pagamento de um salário mínimo vigente à época dos fatos, pelo período de seis meses, contados a partir do desastre, com incidência de juros e correção monetária do INPC. Outrossim, negou provimento ao recurso interposto pela Petrobrás.

Em suma, é a síntese dos fatos e do conteúdo analisado pelo acórdão, o qual será objeto de comentários a seguir, mormente no que tange a relação entre desastres e o Direito.

\section{A PROTEÇÃO JURÍDICA CONTRA DESASTRES}

Após o relatório processual, o relator do referido acórdão assim começa a fundamentação de seu voto: "o caso retratado refere-se a um dos maiores desastres ambientais ocorridos no país" (RIO DE JANEIRO. Tribunal de Justiça do Estado do Rio de Janeiro, 2005, p. 3). Nesse trecho, verifica-se que é utilizada a categoria "desastre" para fazer alusão ao derramamento de óleo na baía de Guanabara. Tendo isso em mente, pergunta-se: o que é desastre para o Direito?

Em primeiro lugar, deve-se frisar que, apesar de entendimentos em sentido contrário ${ }^{3}$, não se faz aqui distinção entre os termos desastre e catástrofe, devendo ambas as expressões serem entendidas como equivalentes. Nesse sentido, observa-se que diversas são as definições para o termo desastre, de forma que algumas condicionam o enquadramento de um evento à categoria de catástrofe apenas se houver a incapacidade reativa da sociedade atingida e o respectivo pedido de ajuda externa ${ }^{4}$, ao passo que outras utilizam um critério estritamente

\footnotetext{
3 Para Carla Amado Gomes, desastre corresponderia ao evento limitado ao território nacional, ao passo que em uma catástrofe, os efeitos seriam maiores e obrigariam o Estado a buscar auxílio externo. Vide GOMES, 2012, p. 23.

4 A exemplo da International strategy for disaster reduction: terminology on disaster risk reduction (ORGANIZAÇÃ̃ DAS NAÇÕES UNIDAS, 2009).
} 
pecuniário e quantitativo para qualificar um evento como sendo catastrófico ${ }^{5}$.

Não obstante os variados conceitos, prefere-se a simplificação da intelecção dessa categoria, entendendo-a como "acontecimentos, que superando o limite da lesão individualizada, atingem direitos, interesses e bens de um número considerável de pessoas ou de uma coletividade" (SOUZA, 2014, p. 34). Isso porque é preciso se ter um conceito dogmático, uma noção mais precisa e juridicamente operável de catástrofe (ANTUNES, 2013, p. 125), sob pena de se ter uma categoria maleável (FARBER, 2012, p. 4), o que implicaria em exclusão e insuficiência de proteção às vítimas do fenômeno catastrófico.

É de se ver que os desastres trazem consigo um rastro de destruição e uma série de consequências fáticas, as quais, por sua vez, são relevantes para o Direito, uma vez que produzem efeitos jurídicos, criando, modificando e extinguindo direitos e obrigações. Diante disso, pode-se afirmar que as catástrofes são fatos jurídicos, ou seja, acontecimentos que, de forma direta ou indireta, acarretam efeito jurídico (VENOSA, 2008, p. 319).

Em tal cenário, o corolário mais evidente desses eventos extremos é o dano, que repercute nas esferas da propriedade privada, da responsabilidade civil, dos contratos, entre outras. Nesse ponto, trata-se especificamente de uma espécie de dano ambiental, qual seja, o denominado dano catastrófico, o qual traz consigo lesões patrimoniais e extrapatrimoniais. Exemplo nítido disso é o caso em análise, no qual os indivíduos formularam em juízo uma pretensão no sentido de obter indenização por danos materiais e morais, em virtude do desastre ocorrido na baía de Guanabara.

\footnotetext{
5 A exemplo do proposto em Catastrophes: insurance issues (INSURANCE INFORMATION INSTITUTE, 2016). Tal instituto condiciona o enquadramento de um evento à categoria de desastre apenas se o valor dos danos cobertos por seguros atingir a casa dos 25 milhões de dólares.
}

Nessa linha, em determinado trecho de seu voto, o relator do acórdão em comento, assim se manifesta: "tal acidente provocou danos ao meio ambiente, trazendo, consequentemente, prejuízos aos pescadores que sobreviviam da estrutura do ecossistema, retirando dali seu sustento e também o de sua família" (RIO DE JANEIRO. Tribunal de Justiça do Estado do Rio de Janeiro, 2005, p. 3).

Sem embargo, apesar de parecer certo preciosismo linguístico ou tecnicismo, não é de bom alvitre, nesse tocante, utilizar o termo "acidente", considerando que, comumente, a ele está associada a ideia de mero acaso ou de excludentes de responsabilidade civil, tais como caso fortuito e força maior. Nesse sentido, Farber nota que é tentador pensar que os desastres são eventos completamente fora do controle humano ou acidentes inevitáveis. Todavia, o homem é capaz de planejar no sentido de reduzir a probabilidade de muitas catástrofes e diminuir os efeitos nocivos, assim como estabelecer procedimentos de reconstrução após o sinistro (FARBER, 2012, p. 3).

Isso assim se dá porque as lesões advindas desses acontecimentos são quase sempre causadas ou, pelo menos, agravadas pela falta de controle adequado e antecipado dos riscos pelo direito fundiário e pelo direito ambiental (FARBER, 2012, p. 3). Logo, resta clarividente que os desastres não são simplesmente acidentes ou acts of God, eles também envolvem as falhas do sistema legal em lidar com os riscos (FARBER, 2012, p. 7). Diante dessa constatação, observa-se que o ordenamento jurídico tem um papel central na prevenção, na resposta e na gestão de riscos e perigos de catástrofes.

Nesse cenário, Carvalho bem observa que o Direito tem a "função de fornecer estabilidade pela normatividade, tanto para evitar como para responder ao caos trazido pelo desastre, provendo expectativas (regulação) às ações de 
antecipação e resposta a estes" (CARVALHO, 2013, p. 406), isto é, o sistema jurídico deve enfrentar o fenômeno catastrófico em uma perspectiva ex ante e ex post ao evento.

Em tal contexto, em sendo o dano catastrófico uma espécie de dano ambiental, infere-se que todo arcabouço jurídico voltado para a tutela do meio ambiente também é aplicável ao fenômeno catastrófico. Assim, de acordo com Lemos (2011, p. 349-363), pode-se apontar três formas de tutela do meio ambiente: a preventiva, a repressiva e a reparadora. A primeira tem como escopo evitar a ocorrência do dano, sendo refletida na adoção do princípio da prevenção e do subprincípio da precaução. Já a segunda, que tem como fulcro a Lei 9.605/1998, diz respeito às sanções penal e administrativa, decorrentes de ações e omissões lesivas ao bem jurídico ambiental. Por sua vez, a terceira é refletida na responsabilidade civil por dano ao meio ambiente (LEMOS, 2011, p. 349-363) ${ }^{6}$. Em razão dos limites do presente trabalho, aqui serão analisadas apenas as tutelas preventiva $\mathrm{e}$ reparadora.

\section{TUTELA AMBIENTAL PREVENTIVA: A GESTÃO DE RISCOS E PERIGOS CATASTRÓFICOS}

Às fls. 6-8 do acórdão em análise, utilizando de trechos de laudos produzidos e juntados aos autos, o relator, parafraseando um dos peritos, aduziu "ter sido o desastre ambiental resultado de falha de gerenciamento, de uma sistemática de subestimação dos riscos ambientais e da resistência a mecanismos de controle ambiental social"( RIO DE JANEIRO. Tribunal de Justiça do Estado do Rio de Janeiro,

\footnotetext{
${ }^{6}$ A autora enxerga a precaução como sendo um princípio, ao contrário dos autores subscritores desses comentários ao acórdão, os quais, na linha de Fiorillo, veem esse comando como sendo um subprincípio, inserido no princípio da prevenção. Ver: FIORILLO, 2013, p. 122-126.
}

2005, p. 6-8). Além disso, novamente se valendo das palavras dos experts, o relator assim afirmou:

\begin{abstract}
Também foi disposto que o acidente poderia ter sido evitado ou ter sido reduzido seu impacto no ecossistema, caso a PETROBRAS "tivesse tomado medidas preventivas de conservação, fiscalização/monitoramento de seus equipamentos, e tivesse maior controle e gerenciamento de seus serviços terceirizados." (RIO DE JANEIRO. Tribunal de Justiça do Estado do Rio de Janeiro, 2005, p. 6). Grifos do autor.
\end{abstract}

Resta nítido, diante do que foi exposto nesses trechos, que a petrolífera deixou de cumprir as medidas preventivas necessárias para que o dano catastrófico fosse evitado, isto é, não houve por parte da Petrobrás, ao que consta do julgado, observância no que diz respeito à tutela ambiental preventiva, além disso, não se verificou um adequado gerenciamento de riscos e perigos catastróficos. Ou seja, os comandos da prevenção e da precaução, que têm por escopo evitar o dano, não foram devidamente observados no caso em comento.

Nesse contexto, é de se notar que o subprincípio da precaução diferencia-se do princípio da prevenção, visto que, enquanto este exige que os riscos e perigos concretos, conhecidos e comprovados sejam eliminados; aquele determina que a ação para evitar o dano seja tomada antes mesmo da evidência científica absoluta. Não obstante, ambos traduzem a máxima "é melhor prevenir do que remediar", estabelecendo a prioridade da adoção de medidas preventivo-antecipatórias em detrimento de medidas repressivo-mediadoras (CARVALHO; DAMACENA, 2013, p. 40).

Em tal seara, como é cediço, ex vi do artigo 225, caput, da Constituição Federal de 1988 (CF/88), a defesa e preservação do equilíbrio ambiental, além de direito, é também dever fundamental, tanto do Poder Público, quanto da coletividade. Desse modo, é imperioso afirmar que todas as decisões e atuações da 
Administração e dos particulares, qualquer que seja a situação da vida, devem ser pautadas e devem tomar como critério o princípio da prevenção e o subprincípio da precaução. Portanto, pode-se dizer que os indigitados comandos regem a atuação de todas as pessoas, naturais ou jurídicas, de direito público ou privado, visando concretizar uma tutela preventiva na seara ambiental.

Como corolário de tais normas, surge, para o Estado e para os particulares, o dever de prevenir o dano catastrófico, o que é feito através da gestão de riscos e perigos catastróficos, tendo em vista que, do ponto de vista de jurídico, interessa não só as catástrofes, mas também o risco catastrófico. Como bem ensina Antunes (2013, p. 138), uma coisa é o desastre, outra coisa é o risco de desastre. Enquanto o primeiro diz respeito à apreensão de um fato (ou conjunto de fatos) e é um acontecimento, o segundo releva da apreensão de uma álea e, por sua vez, é uma incerteza ou eventualidade.

Nesse sentido, consoante aduz Farber (2012, p. 6), os riscos dos danos oriundos de desastres não estão fora do controle humano, motivo pelo qual se pode inferir que cabe ao Direito estabelecer normas visando a gestão dos riscos e perigos catastróficos, levando sempre em consideração os seus fatores agravantes: vulnerabilidade e exposição.

O IPCC - Intergovernmental Panel on Climate Change (2012), nesse tocante, define vulnerabilidade como sendo "a propensão ou predisposição para ser negativamente afetado", e exposição como a "presença de pessoas, atividades econômicas, recursos e serviços ecológicos, infra-estruturas e bens econômicos, sociais ou culturais em locais que possam ser negativamente afetados".

Em que pese ser difícil prevenir o desastre em si mesmo, haja vista ser imprevisível; podese - e é necessário - prevenir o risco catastrófico, considerando que este é determinado pela vulnerabilidade e pela exposição. Isso é possível através de duas vias: aumentando a resiliência ou diminuindo a exposição (ANTUNES, 2013, p. 142), as quais somente serão exitosas se forem inseridas dentro de uma adequada gestão de riscos e perigos envolvendo desde a prevenção e o planejamento até a resposta e compensação.

Nessa senda, Farber propõe que o gerenciamento de riscos e perigos de desastres seja realizado através do "Ciclo do Direito dos Desastres", que se trata de um conjunto de estratégias envolvendo os seguintes estágios, os quais se relacionam uns com os outros: mitigação, ocorrência do evento catastrófico, resposta de emergência, compensação e, por derradeiro, a reconstrução (FARBER, 2012, p. 6). Com efeito, a gestão dos riscos e perigos de maneira integrada e adequada, envolvendo todas as fases de forma circular, serviria para a prevenção e o planejamento de eventos posteriores, de modo que haveria, nessa situação, a aplicação do aprendizado do passado no presente, obtendo-se reflexos no futuro (FARBER, 2012, p. 7) ${ }^{7}$.

No caso em comento, os riscos e perigos de derramamento de óleo na baía de Guanabara eram concretos, conhecidos e comprovados, uma vez que, em 10 de março de 1997, quase três anos antes dos fatos aqui analisados, ocorreu um fato semelhante com o mesmo duto PE-II, tendo sido derramados cerca de três milhões de litros de combustível no meio ambiente. É indubitável que o princípio da prevenção, bem como seu corolário, uma adequada gestão de riscos e perigos catastróficos visando evitar o dano, não foram observados pela Petrobrás nessa situação, razão pela qual um dos peritos citados no acórdão foi categórico ao afirmar que a catástrofe poderia ter sido evitada, ou mesmo seus efeitos no meio ambiente poderiam ter sido

${ }^{7}$ Para maiores detalhes, ver CARVALHO; DAMACENA, 2013, p. 33 e 70-79. 
mitigados, caso a petrolífera "tivesse tomado medidas preventivas de conservação, fiscalização/monitoramento de seus equipamentos" (RIO DE JANEIRO. Tribunal de Justiça do Estado do Rio de Janeiro, 2005, p. 7).

Nessas situações, conquanto seja preferível, sob a ótica da tutela preventiva, evitar-se o dano, uma vez tendo este se concretizado, haja vista ser a compensação também uma fase da gestão de riscos e perigos, é necessário que ocorra a tutela reparadora e esta, por sua vez, deve se dar através do instituto da responsabilidade civil, que é fundamentado, em caso dos desastres, sobretudo pelas normas de Direito Ambiental e pelas regras e princípios gerais previstos na Constituição Federal, no Código Civil, e na Lei 6.938/1981. In casu, vale dizer: embora se preferisse que a petrolífera gerenciasse de maneira adequada os riscos e perigos e observasse os deveres de evitar o dano catastrófico, tendo ocorrido este, as vítimas têm o direito de serem indenizadas pelas lesões sofridas.

\section{TUTELA AMBIENTAL REPARADORA: A RESPONSABILIDADE CIVIL EM MATÉRIA CATASTRÓFICA}

Como visto alhures, a tutela ambiental reparadora é realizada mediante o instituto da responsabilidade civil. Outrossim, viu-se que, em razão de o dano catastrófico ser uma espécie de dano ambiental, todo arcabouço jurídico voltado para a tutela do meio ambiente também é aplicável ao fenômeno catastrófico. Logo, inferese que todo aparato jurídico relativo à tutela ambiental reparadora pode ser usado para a compensação dos danos catastróficos.

Em tal cenário, quando se está a falar em responsabilidade civil, deve-se ter em mente que este instituto jurídico consiste em um dever jurídico de reparação, o qual decorre de uma lesão causada ou da violação de uma obrigação de evitar o dano, tendo, como supedâneo, previsão legal ou contratual, sendo que, em alguns casos, é necessário se comprovar o elemento acidental, culpa lato sensu (negligência, imprudência, imperícia ou dolo). Havendo necessidade de prova da culpa, diz-se subjetiva a responsabilidade, ao passo que não havendo essa exigência, fala-se em responsabilidade civil objetiva.

Para que reste configurado o dever jurídico de reparação, alguns elementos são necessários, são eles: dano $^{8}$, nexo de causalidade e conduta (ação ou omissão). Além disso, não se há de ter causas excludentes de responsabilidade civil. Assim, havendo um dever jurídico originário (uma obrigação), em sendo ele descumprido, desde que presentes os requisitos acima elencados, surgirá para o agente da conduta o dever jurídico sucessivo, ou seja, a responsabilidade civil.

Fazendo um juízo de subsunção ao caso do acórdão analisado, nota-se, de um lado, que a petrolífera tinha um dever jurídico originário e fundamental de manter o meio ambiente ecologicamente equilibrado, estando vinculada às normas da prevenção e da precaução e, por conseguinte, a uma adequada gestão de riscos e perigos, com mais razão ainda porque um evento semelhante ocorrera quase três anos antes. De outro lado, verifica-se que a omissão dessa empresa em gerir adequadamente os riscos e perigos catastróficos, consoante laudos periciais, foi causa do derramamento de óleo na baía de Guanabara, que pode ser enquadrado na categoria de desastre, o qual, por sua vez, provocou diversos danos catastróficos. Em outras palavras: houve conduta, liame causal e dano, além de não ter se verificado qualquer causa excludente de responsabilidade. Logo, da violação do dever jurídico originário, o adequado gerenciamento de riscos e perigos catastróficos,

8 Para maiores detalhes sobre a categoria jurídica "dano", ver: SILVA, 2015, p. 333-348. 
surge para a Petrobrás o dever jurídico sucessivo, a responsabilidade civil. Portanto, escorreita se encontra a decisão ao imputar a responsabilidade à petrolífera, apesar disso, alguns pontos do acórdão carecem de uma análise mais apurada.

Um dos pontos a se debruçar é o dano que foi sofrido pelos autores da ação judicial em questão, sua espécie e suas características. Nesse caso, de acordo com a decisão:

\begin{abstract}
O desastre ecológico do derrame de 1,3 milhões de litros de óleo na baía afetou o ambiente da flora e fauna marinhas e ribeirinhas, transmudou em cena dantesca sua ilustração estética como área de preservação e turismo, causou males ao tratamento higiênico de toda a população local e, pior que todos estes males, atingiu direta e pessoalmente as centenas de milhares de pessoas de baixa renda que vivia da pesca e coleta de animais no entorno e nas águas. As repercussões maléficas não alcançam apenas a sobrevivência econômica destas populações, mas repercutem diretamente na paz familiar de cada entidade dependente da pesca e coleta. As desavenças em razão da perda do trabalho (já parco e miserável) têm consequências desastrosas nas famílias de baixa renda. Os mais atingidos, ao cabo, são os infantes, receptáculos familiares dos desajustes dos casais empobrecidos. (RIO DE JANEIRO. Tribunal de Justiça do Estado do Rio de Janeiro, 2005, p. 8-9).
\end{abstract}

Não há dúvidas de que se está a tratar, in casu, de danos catastróficos, uma vez que são oriundos de um evento enquadrado na categoria de desastre. Nesse sentido, vê-se que, assim como os demais de seu gênero (dano ambiental lato sensu), os danos catastróficos não se apresentam linearmente (causalidade simples), mas, antes, possuem uma causalidade complexa, considerando que são, amiúde, "produtos de várias causas concorrentes, simultâneas ou sucessivas" (LEITE; CARVALHO, 2007, p. 78).

Contudo, não obstante essas espécies de causas, na esteira de Benjamin, constata-se que o direito ambiental pátrio "não admite qualquer distinção - a não ser no plano do regresso - entre causa principal, causa acessória e concausa" (BENJAMIN, 1998, p. 45). Em virtude disso, do que se extrai do julgado em análise, não prospera o argumento sustentado pela Petrobrás, no sentido de se ver isenta da responsabilidade civil, de que a poluição pré-existente na baía de Guanabara era pública e notória. Assim, resta assente que qualquer que seja a ação ou omissão do sujeito, influindo no resultado danoso, mesmo que indiretamente, trata-se de conduta suficiente para ensejar a inclusão do agente no polo passivo da demanda de responsabilidade civil por danos ao meio ambiente.

Outrossim, observa-se que, no caso em comento, está-se diante de um dano catastrófico pessoal, o qual, assim como o dano ambiental pessoal, "nada mais é do que um prejuízo pessoal ou patrimonial sofrido pela via do ataque ao meio ambiente" (BENJAMIN, 1998, p. 49) ${ }^{9}$. Aqui, os bens jurídicos tutelados são a integridade humana e o patrimônio, dando ensejo ao pedido de reparação de danos materiais e morais decorrentes do desastre. Por outro lado, tem-se o dano catastrófico ecológico, o qual, assim como o dano ambiental stricto sensu, atinge tão somente o meio ambiente enquanto bem jurídico autônomo. Vê-se, então, que um mesmo fato pode ocasionar diversas modalidades de dano.

Outro ponto a se destacar é que, em se tratando de responsabilidade civil por danos ao meio ambiente, ex vi do artigo $14, \S 1 .^{\circ}$, da Lei 6.938/1981, dispositivo normativo inclusive citado no julgado em comento, a responsabilidade civil do poluidor é objetiva, ou seja, não há a necessidade de prova da culpa. Nesse tocante, no que tange à responsabilidade civil objetiva, tem-se duas teorias que se destacam, quais sejam, a do risco criado e a do risco integral.

\footnotetext{
9 O autor fala tão somente na distinção entre dano ambiental pessoal e dano ecológico (dano ambiental stricto sensu). Considerando ser o dano catastrófico uma espécie do gênero dano ambiental, chegou-se à ilação de que o mesmo raciocínio se aplica à matéria envolvendo desastres.
} 
Em linhas gerais, a distinção entre elas se encontra na admissão ou não das excludentes de responsabilidade civil. Enquanto a do risco criado as admite, o mesmo não se pode dizer da teoria do risco integral. Nessa senda, a jurisprudência do Superior Tribunal de Justiça - a exemplo do recente julgamento do Recurso Especial n. ${ }^{\circ}$ 1.363.107/DF (BRASIL. Superior Tribunal de Justiça, 2013) - é pacífica no entendimento de que a responsabilidade por dano ambiental é informada pela teoria do risco integral, sendo descabida a invocação de excludentes de responsabilidade civil para afastar a obrigação de indenizar.

Contudo, in casu, apesar de em determinado ponto, o relator ter se manifestado no sentido de que a responsabilidade da Petrobrás era integral "pelas consequências danosas ao meio ambiente como um todo e às comunidades locais, em particular", em outro trecho da decisão, o aludido julgador assim se manifestou:

Como a culpa não é elemento da responsabilidade objetiva, para haver a atribuição de responsabilidade, basta a demonstração do fato lesivo, o dano sofrido e a respectiva relação de causalidade, sem necessidade de perquirição da culpa, transferindo-se para o causador do dano a prova da ocorrência de alguma causa de exclusão. (RIO DE JANEIRO. Tribunal de Justiça do Estado do Rio de Janeiro, 2005, p. 4). Grifo Nosso.

Em que pese não ter feito referência à teoria do risco criado em momento algum da decisão, pode-se entender, pelo trecho extraído, que essa seria a teoria aplicável ao dano catastrófico. Nota-se que ora se fala em teoria do risco integral, ora se utiliza das premissas da teoria do risco criado. A despeito de se ter chegado à imputação do dever de reparação ao poluidor, ou seja, o resultado ter sido satisfatório nesse específico ponto, ao final, não se tem como saber a qual das teorias o relator se filia. Nesse tocante, por uma questão técnica, dever-se-ia ter coerência e uniformidade.

Por derradeiro, outro ponto a se olhar com cautela no referido acórdão diz respeito à fixação da indenização por danos materiais. Nesse capítulo da decisão, a Petrobrás foi condenada a pagar o valor de um salário mínimo mensal pelo período de seis meses a título de lucros cessantes, uma vez que não se tinha nos autos prova da renda mensal percebida pelos autores da ação judicial, os quais eram pescadores e exerciam suas atividades na baía de Guanabara.

In casu, verifica-se que um dos princípios basilares do direito ambiental brasileiro não foi observado, qual seja, o princípio da reparabilidade integral do dano ambiental, segundo o qual "são vedadas todas as formas e fórmulas, legais ou constitucionais, de exclusão, modificação ou limitação da reparação ambiental, que deve ser sempre integral" (BENJAMIN, 1998, p. 19).

Ora, se um dos laudos periciais juntados aos autos constatou ser necessário cerca de dez anos para o meio ambiente se recompor na baía de Guanabara (o que inclui a atividade pesqueira, que foi afetada pelo desastre), tendo isso sido alegado por Paulo Gilson da Costa Almeida e Vilson da Costa Gomes, em suas razões recursais, por que a indenização foi fixada apenas para o período de seis meses? Não há dúvidas de que houve inobservância por parte do tribunal no que tange ao aludido princípio.

\section{CONCLUSÃO}

Da análise do desastre, bem como do acórdão em análise, pôde-se chegar a algumas conclusões. Passa-se à síntese delas.

No que diz respeito à relação entre desastres e o Direito, viu-se que desastres são fatos jurídicos, podendo ser entendidos como sendo aqueles acontecimentos, que superando o limite da lesão individualizada, atingem direitos, interesses e bens de um número considerável de 
pessoas ou de uma coletividade. O corolário mais evidente desses eventos extremos é o dano, que repercute nas esferas da propriedade privada, da responsabilidade civil, dos contratos, entre outras. Nesse ponto, trata-se especificamente de uma espécie de dano ambiental, o denominado dano catastrófico.

Em tal cenário, viu-se que o ordenamento jurídico tem um papel central na prevenção, na resposta e na gestão de riscos e perigos de catástrofes, devendo o sistema jurídico enfrentar o fenômeno catastrófico em uma perspectiva ex ante e ex post ao evento, o que se refere às tutelas ambientais preventiva e reparadora, respectivamente.

A primeira tem por objetivo evitar o dano, sendo informada pelo princípio da prevenção e pelo subprincípio da precaução, tendo, como corolário, a gestão de riscos e perigos catastróficos. Por sua vez, a segunda tem por objetivo reparar o dano catastrófico, sendo refletida no instituto jurídico da responsabilidade civil.
Já no que tange ao acórdão analisado, é de se reconhecer que a decisão, em linhas gerais, afigurou-se escorreita, uma vez que reconheceu, ainda que não utilizando esses termos, uma tutela ambiental preventiva condizente ao gerenciamento de riscos e perigos catastróficos. Ademais, é de se elogiar o fato de o acórdão ter reformado a sentença no que diz respeito à existência de danos materiais na modalidade lucros cessantes.

Todavia, a decisão em análise pecou na inobservância do princípio da reparabilidade integral do dano ambiental, uma vez que fixou a indenização por danos materiais pelo período de apenas seis meses, enquanto o meio ambiente, incluindo a atividade de subsistência dos lesados, demorou cerca de dez anos para se recompor.

Além disso, não houve coerência e uniformidade no acórdão no que tange à responsabilidade civil objetiva, considerando que ora se falou em teoria do risco integral, ora se utilizou das premissas da teoria do risco criado.

\section{REFERÊNCIAS}

ANTUNES, Tiago. O risco climático na sua dimensão catastrófica. In: GOMES, Carla Amado; SARAIVA, Rute. Actas do colóquio catástrofes naturais: uma realidade multidimensional. Lisboa: Instituto de Ciências Jurídico-Políticas, 2013.

BENJAMIN, Antonio Herman Vasconcellos e. Responsabilidade civil pelo dano ambiental. Revista de Direito Ambiental, v. 3, n. 9, p. 5-52, 1998.

BRASIL. Ministério do Meio Ambiente. Conselho Nacional do Meio Ambiente. Relatório sobre o impacto ambiental causado pelo derramamento de óleo na Baía de Guanabara. Brasília, 2001. Disponível em: <www.mma.gov.br/port/conama/processos/67B2E6A7/artigo5.doc>. Acesso em 14 jul. 2016.

CARVALHO, Délton Winter de. As mudanças climáticas e a formação do direito dos desastres. Novos Estudos Jurídicos (Online), v. 18, p. 397-415, 2013.

CARVALHO, Délton Winter de; DAMACENA, Fernanda Dalla Libera. Direito dos desastres. Porto Alegre: Livraria do Advogado, 2013.

FARBER, Daniel. Disaster law and emerging issues in Brazil. Revista de estudos constitucionais, hermenêutica e teoria do direito, São Leopoldo: UNISINOS, v. 4, n. 1, p. 2-15, 2012. 
FIORILlo, Celso Antonio Pacheco. Curso de direito ambiental brasileiro. 14. ed. São Paulo: Saraiva, 2013.

GOMES, Carla Amado. A gestão do risco de catástrofe natural. In: GOMES, Carla Amado (Coord.). Direito(s) das catástrofes naturais. Lisboa: Almedina, 2012.

GOMES, Carla Amado (Coord.). Direito(s) das catástrofes naturais. Lisboa: Almedina, 2012.

GOMES, Carla Amado; SARAIVA, Rute. Actas do colóquio catástrofes naturais: uma realidade multidimensional. Lisboa: Instituto de Ciências Jurídico-Políticas, 2013.

INSURANCE INFORMATION INSTITUTE. Catastrophes: insurance issues, 2016. Disponível em : <http://www.iii.org/issue-update/catastrophes-insurance-issues>. Acesso em 10 jan. 2016.

INTERGOVERNMENTAL PAINEL ON CLIMATE CHANGE. Summary for policymakers. Cambridge: Cambridge University, 2012. Disponível em <https://www.ipcc.ch/pdf/specialreports/srex/SREX_Full_Report.pdf>. Acesso em 10 jun. 2015.

LEITE, José Rubens Morato; CARVALHO, Délton Winter de. Nexo de causalidade na responsabilidade civil por danos ambientais. Revista de Direito Ambiental, v. 47, p. 76-95, 2007.

LEMOS, Patrícia Faga Iglecias. Responsabilidade civil e dano ao meio ambiente: novos rumos. In: MILARÉ, Édis; MACHADO, Paulo Affonso Leme (Orgs.). Doutrinas essenciais: Direito ambiental. v. 5. Responsabilidade em matéria ambiental. São Paulo: Revista dos Tribunais, 2011.

MILARÉ, Édis; MACHADO, Paulo Affonso Leme (Orgs.). Doutrinas essenciais: Direito ambiental. v. 5. Responsabilidade em matéria ambiental. São Paulo: Revista dos Tribunais, 2011.

ORGANIZAÇÃO DAS NAÇÕES UNIDAS. International strategy for disaster reduction: terminology on disaster risk reduction, 2009. Disponível em: <http://www.unisdr.org/files/7817_UNISDRTerminologyEnglish.pdf>. Acesso em 10 jan. 2016.

RIO DE JANEIRO. Tribunal de Justiça do Estado do Rio de Janeiro. Apelação Cível $n^{\circ} 0026225$ 19.2005.8.19.0021, 2005. Disponível em: <www.tjrj.jus.br>. Acesso em 14 jul. 2016.

SILVA, Clóvis V. do Couto e. O conceito de dano no direito brasileiro e comparado. Revista de Direito Civil Contemporâneo, v. 02, p. 333-348, 2015.

SOUZA, Carlos Eduardo Silva e. Danos catastróficos: da gestão de riscos e perigos à reparação. Tese de Doutorado apresentada à Faculdade Autônoma de Direito de São Paulo, 2014.

SUPERIOR TRIBUNAL DE JUSTIÇA. Recurso Especial $\mathrm{n}^{\mathrm{o}}$ 1.363.107/DF. Disponível em <http:www.stj.jus.br>. Acesso em 19 set 2016.

VENOSA, Sílvio de Salvo. Direito civil: parte geral. Coleção direito civil. 8. ed. v. 1. São Paulo: Atlas, 2008. 
Recebido em: 19/09/2016 Aceito em: 28/12/2016 
